\title{
Characteristics of Carbon Nanotube Relay
}

\author{
Manu Mitra* \\ Alumnus of University of Bridgeport, United States
}

*Corresponding author: Alumnus of University of Bridgeport, United States.

\begin{abstract}
Relays are electromechanical switches which are normally used to control high power electrical machineries. It is very important part for a control a single circuit or multiple circuits either with a low power signal or high-power signals. In this paper Carbon nanotube Relay has been used with trench of gold as electrode material and characteristics of carbon nanotube relay such as histogram of outer diameters, histogram of inner diameters, histogram of lengths, pull in voltage vs outer diameter, pull back voltage vs outer diameter, pull in voltage vs length, pull back voltage vs length, pullback voltage vs pull in voltage with various samples of 10 , 100, 1000 and 10,000 and its values are simulated and its values are noted.
\end{abstract}

Keywords: Carbon nanotube relay; Relays; Carbon nanotube electromagnetic relay; Pull in voltage, Pull back voltage

\section{Introduction}

Carbon nanotubes are considered to be one of the most favorable materials beyond Complementary Metal-Oxide Semiconductor (CMOS) devices in the front end and as well as back end level. Development of this new organic material is becomes important because of dimensions are in the scale of nanometer and its outstanding electrical performance such as ballistic conduction, its current density is around $>109 \mathrm{~A} / \mathrm{cm} 2$, its Young's modulus is around $1 \mathrm{TPa}$ and its low mass density is around $\rho=1300 \mathrm{~kg} / \mathrm{m} 3$. Among other applications and advantages of Carbon Nanotube, for instance interconnections, sensors, transistors, memory, etc. a specific use of is to build Nano-electro-mechanical devices such as resonators and switches. These Nano electromechanical devices based on carbon nanotubes demonstrates a large current density drive and high speed of operation when compared to metal-based Nano electro mechanical systems. Most of the Carbon nanotube nanoelectromechanical switches relays are configuration based on one single movable nanotube and its DC characterization. A very large integration of nanoelectromechanical devices requires usage of high density aligned arrays of nanotubes, created in precise locations that could be patterned into a well-defined and controlled configuration [1].

\section{Literature Review}

Unlikeothersolid-stateswitches, carbonnanoelectromechanical devices have low off states currents; one of the reasons because their conducting tracks are physically isolated. In specific carbon nanotubes relays have significant mechanical and electrical properties compared to other metal devices that make them exceptional contender for the design of carbon nanotube relays. They are extremely stiff, they can withstand very large mechanical strains, because of their low mass and chemical inertness make them favorable for enabling low-leakage, low power and highspeed switching devices that also have significant prospective to function under extreme environments. Carbon Nanotubes have been already used in variety of applications ranging from memory devices to Nano tweezers. Voltage measurements of these devices demonstrated a well-defined off and on states. Typical power dissipation per switching even was very low, in hundreds of Nano watts. It also demonstrates that switching occurred in forward and reverse bias conditions which indicates that field emission, a polarity depended phenomenon which is unlikely to take place at these voltages. In addition, switching times of these devices were measured only a few nanoseconds [2] (Figure 1). 


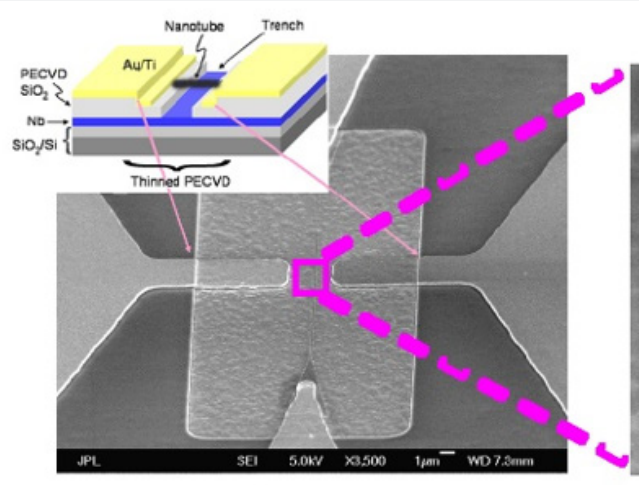

(a)

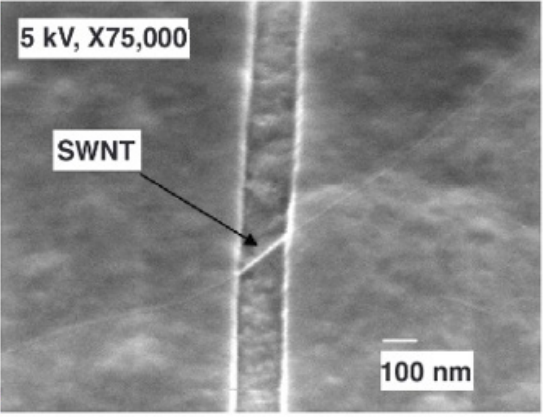

(b)

Figure 1: (a) Low-magnification scanning electron microscope (SEM) image of a nanoelectromechanical (NEM) device. The inset shows the device schematic.

(b) High-magnification SEM image showing a single-walled carbon nanotube (SWNT) bridging the nanotrench beneath it.

\section{Carbon Nanotube Relay Simulations}

\section{Carbon nanotube relay for 10 samples}

A simulation for carbon nanotube relay was performed for 10 samples with electrode material as gold [3] (Figure 2-9) (Table 1).

Table 1: Simulation Notes for Carbon Nanotube Relay as 10 Samples.

\begin{tabular}{|c|c|c|}
\hline SI No & Simulation Specifications & Value \\
\hline 1 & Number of samples & 10 \\
\hline 2 & Trench of Electrode material & Gold \\
\hline 3 & Width & $20 \mathrm{~nm}$ \\
\hline 4 & Depth & $100 \mathrm{~nm}$ \\
\hline 5 & Average outer diameter & $4.2 \mathrm{~nm}$ \\
\hline 6 & Standard deviation of other diameter & $1.25 \mathrm{~nm}$ \\
\hline 7 & Inner diameter to outer diameter & 0.5 \\
\hline 8 & ratio & $100 \mathrm{~nm}$ \\
\hline 9 & Average length & $2.25 \mathrm{~nm}$ \\
\hline 10 & Standard deviation of length & $2.88 \mathrm{~A}$ \\
\hline 11 & Width of contact surface & $1300 \mathrm{Gpa}$ \\
\hline
\end{tabular}

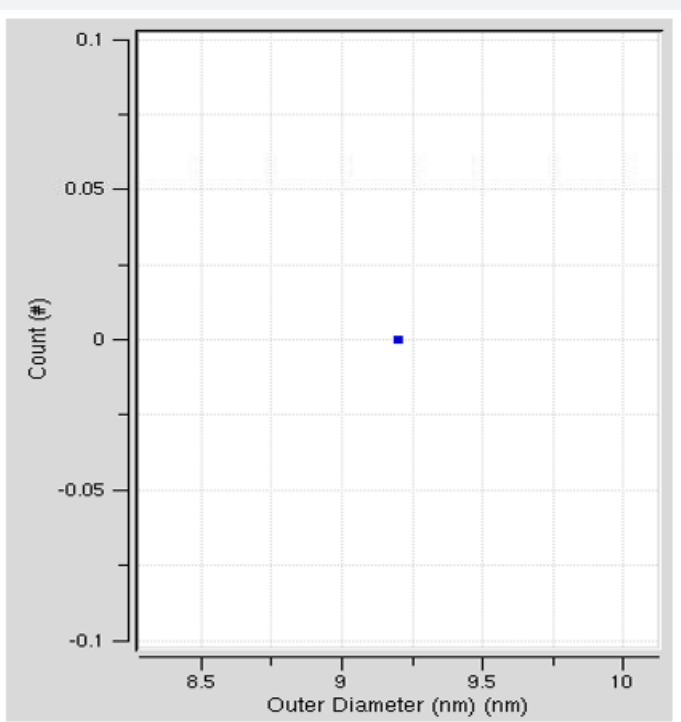

Figure 2: Illustrates Histogram of outer diameters for sample 10.

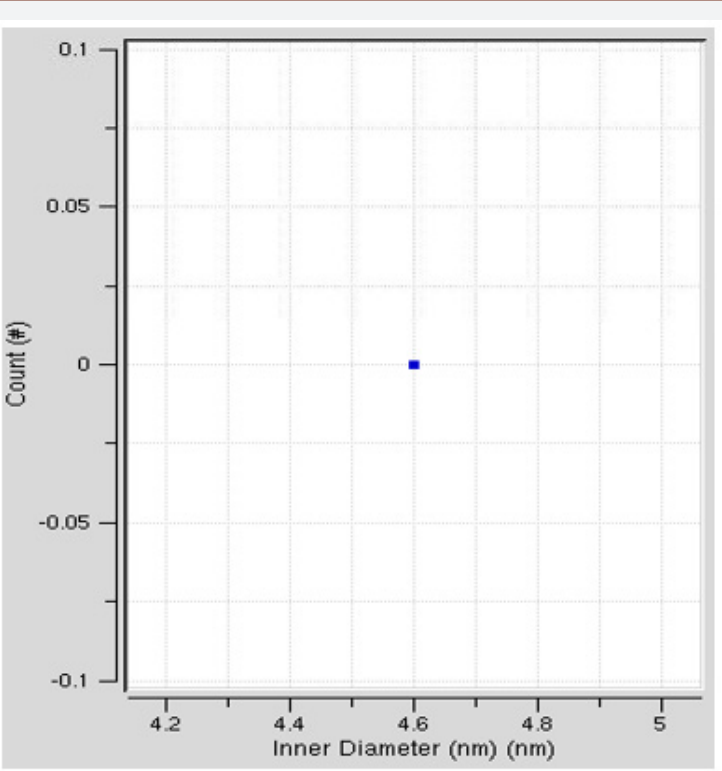

Figure 3: Illustrates Histogram of inner diameters for sample 10.

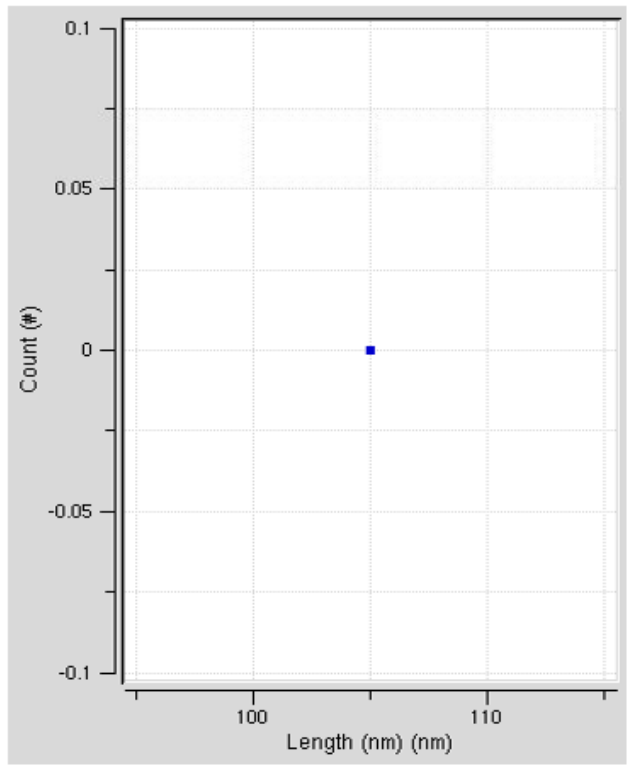

Figure 4: Illustrates Histogram of lengths for sample 10. 


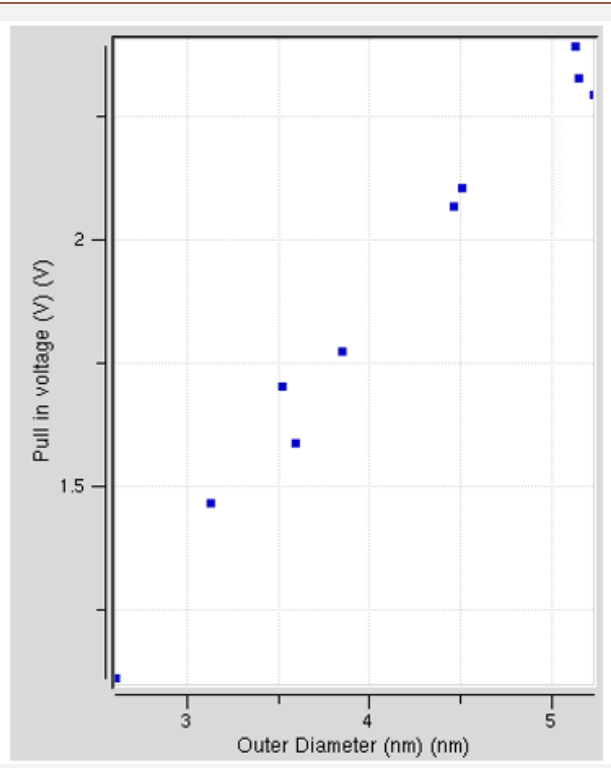

Figure 5: Illustrates Histogram of lengths for sample 10.

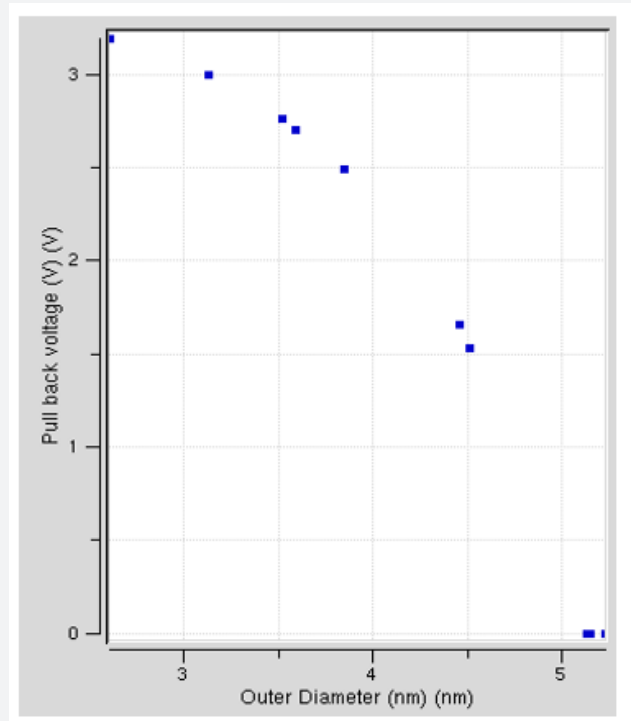

Figure 6: Illustrates pull back voltage vs outer diameter for sample 10.

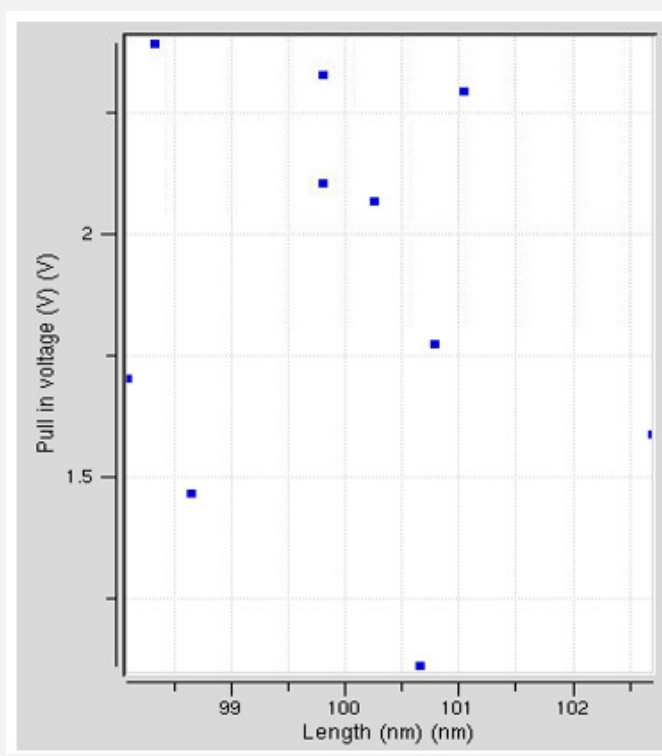

Figure 7: Illustrates Pull in voltage vs length for sample 10.

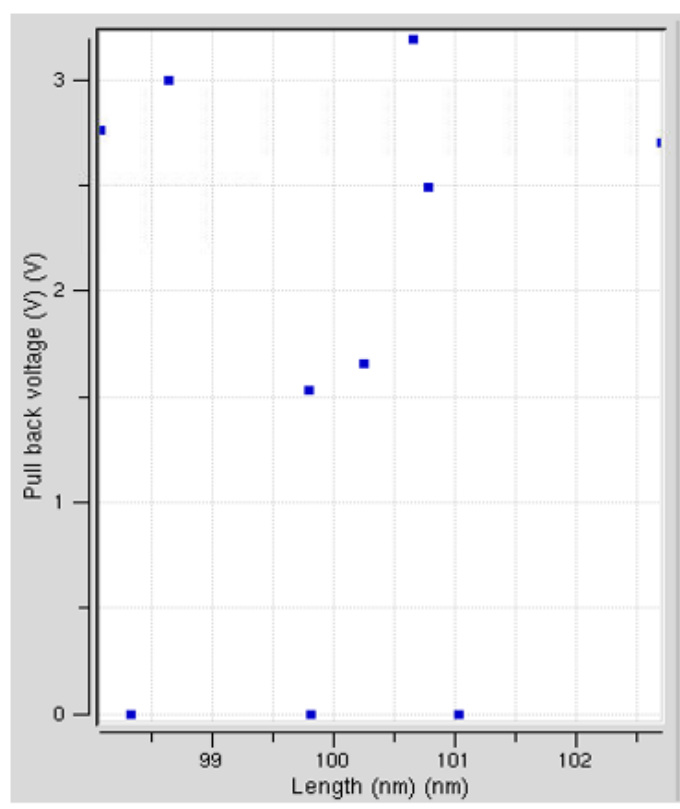

Figure 8: Illustrates Histogram of lengths for sample 10.

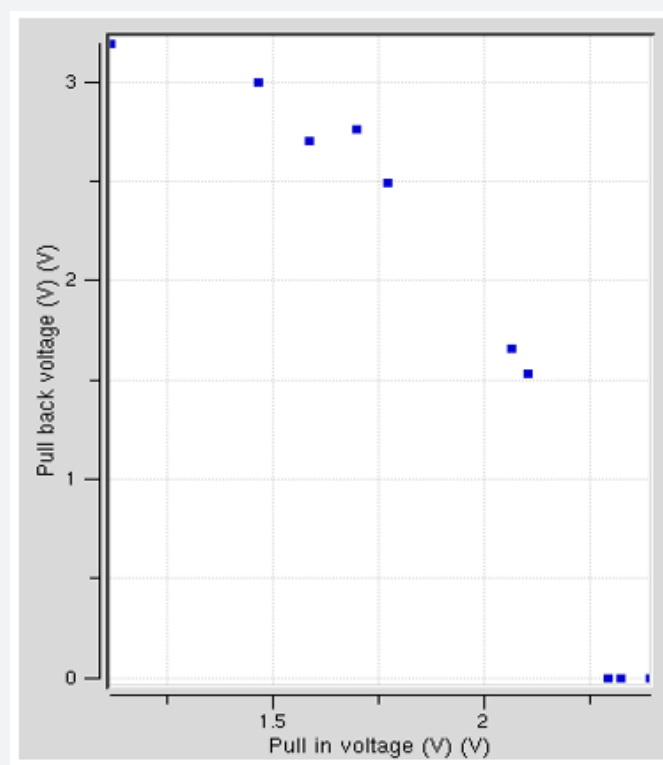

Figure 9: Illustrates pull back voltage vs Pull in voltage for sample 10 .

\section{Observations}

- $\quad$ In Figure 2, histogram of outer diameter was $0 @ 9.2$ nm.

- In Figure 3, histogram of inner diameter was $0 @ 4.6$ nm.

- In Figure 4, histogram of length was 0 @ 105 nm.

- In Figure 5, pull in voltage vs outer diameter: Highest was 2.39264V@5.12987nm and lowest was 1.11182V@ $2.60136 \mathrm{~nm}$.

- In Figure 6, pull back voltage vs outer diameter: highest value was 3.19393V @ 2.60136nm and lowest value was 0 @ $5.22644 \mathrm{~nm}$.

- In Figure 7, pull in voltage vs length: highest value was 2.39264V@98.3251nm and lowest value was 1.11182V @ $100.653 n m$. 
- In Figure 8, pull back voltage vs length: highest value was 3.19393V @ 100.653nm and lowest value was 0V @ 98.3251nm,0V@ 99.8055nm and 0V @ 101.034nm.

- In Figure 9, pull back voltage vs pull in voltage: highest value was 3.19393V @ 1.11182V and lowest value was 0V @ 2.29341V,0V @2.32754V and 0V @ 2.39264V.

\section{Carbon nanotube relay for 100 samples}

A simulation for carbon nanotube relay was performed for 100 samples with electrode material as gold (Figure 10-17) (Table 2).

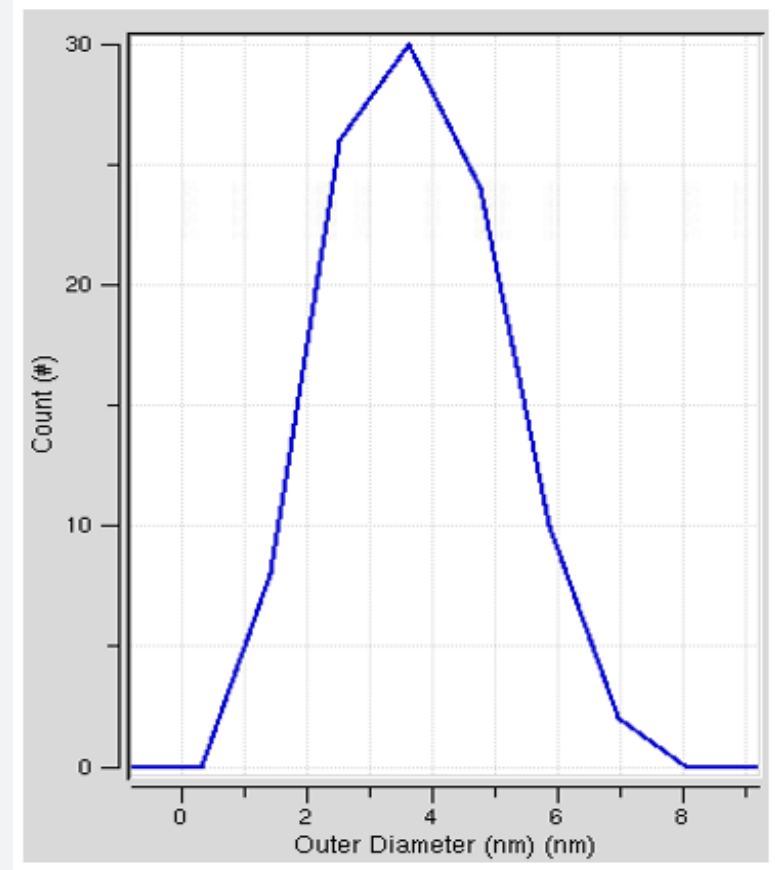

Figure 10: Illustrates Histogram of outer diameters for sample 100.

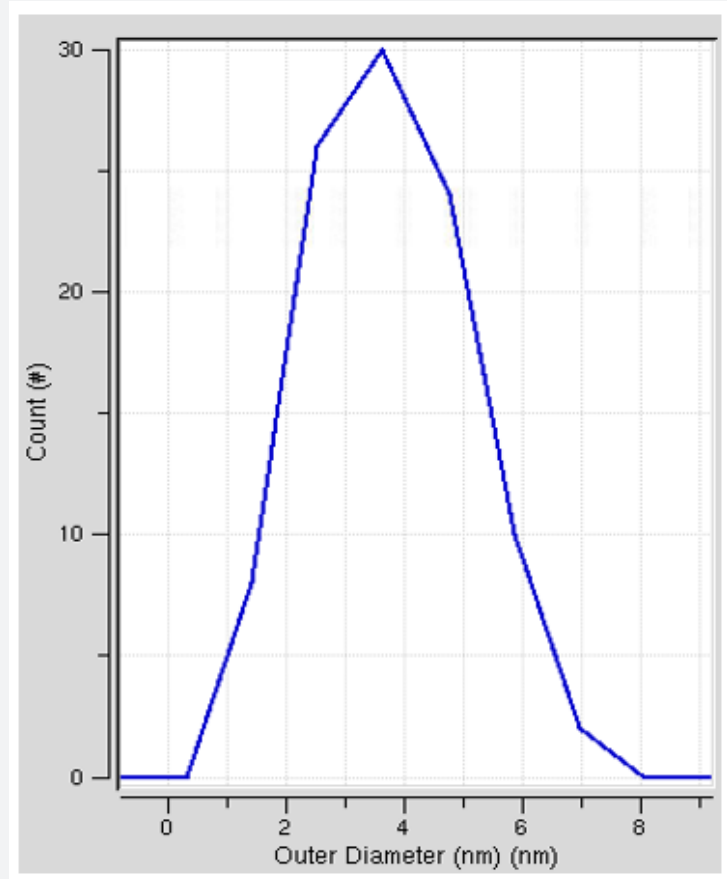

Figure 11: Illustrates Histogram of outer diameters for sample 100.

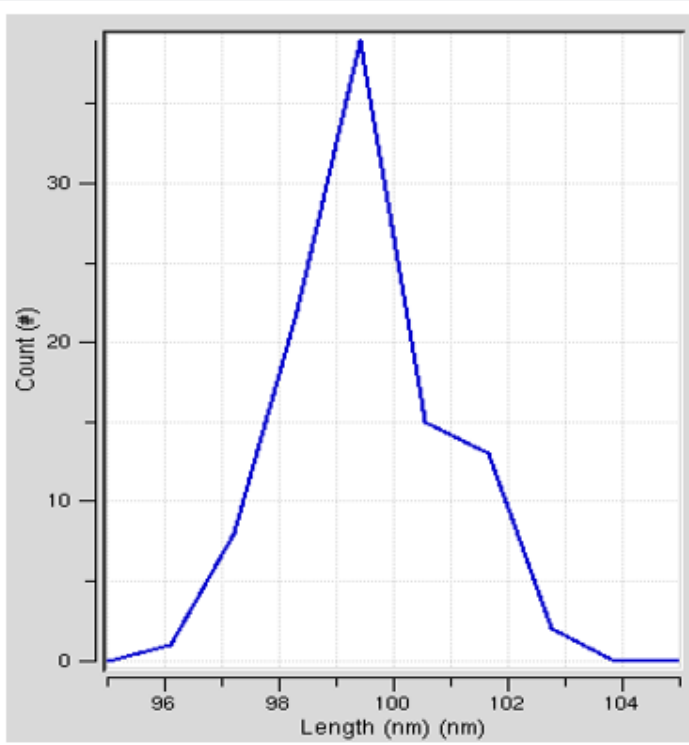

Figure 12: Illustrates Histogram of lengths for sample 100.

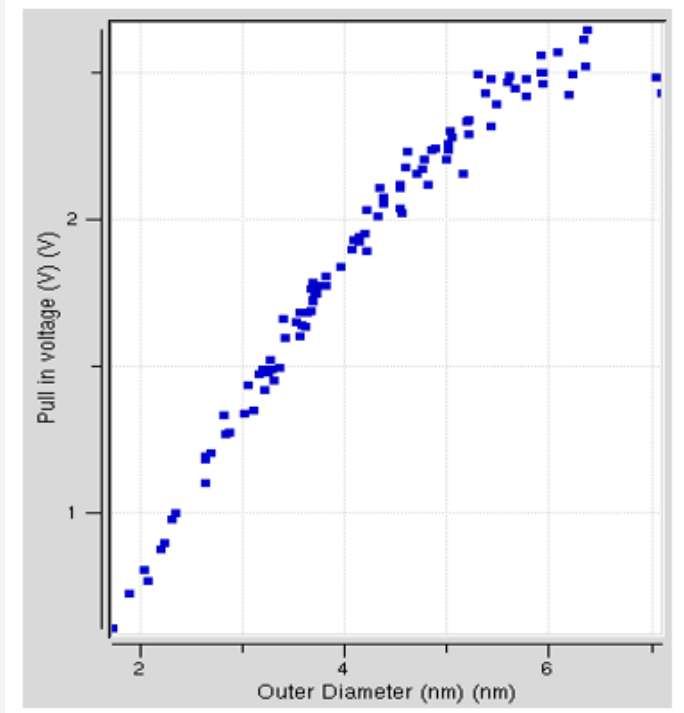

Figure 13: Illustrates pull in voltage vs outer diameter for sample 100.

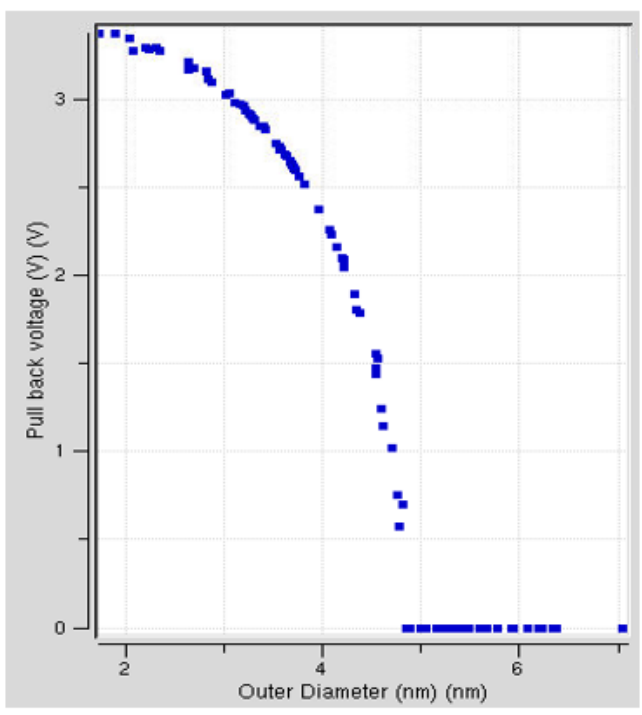

Figure 14: Illustrates pull back voltage vs outer diameter for sample 100. 


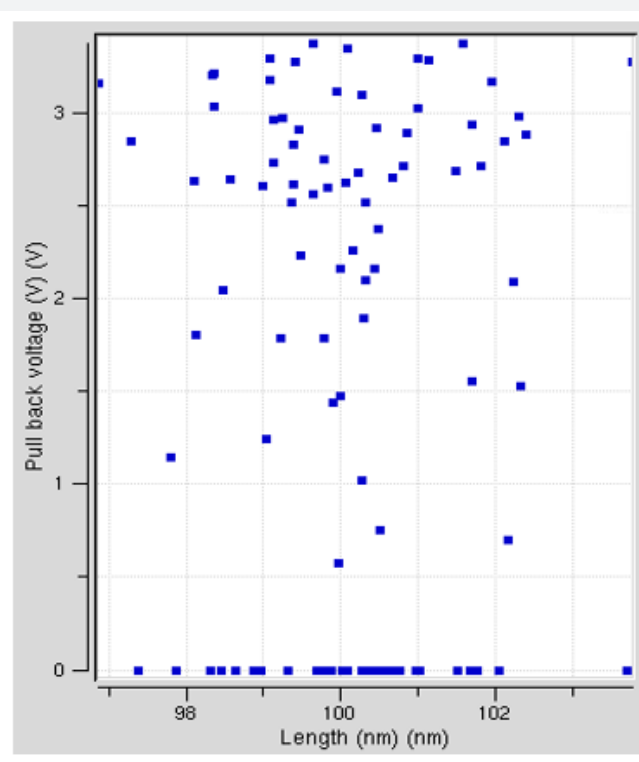

Figure 15: Illustrates Pull in voltage vs length for sample 100.

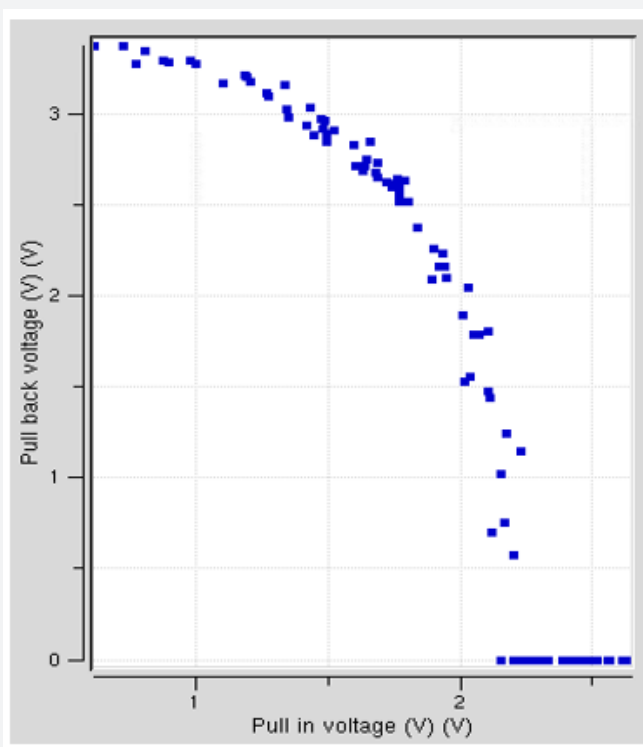

Figure 16: Illlustrates Pull back voltage vs length for sample 100.

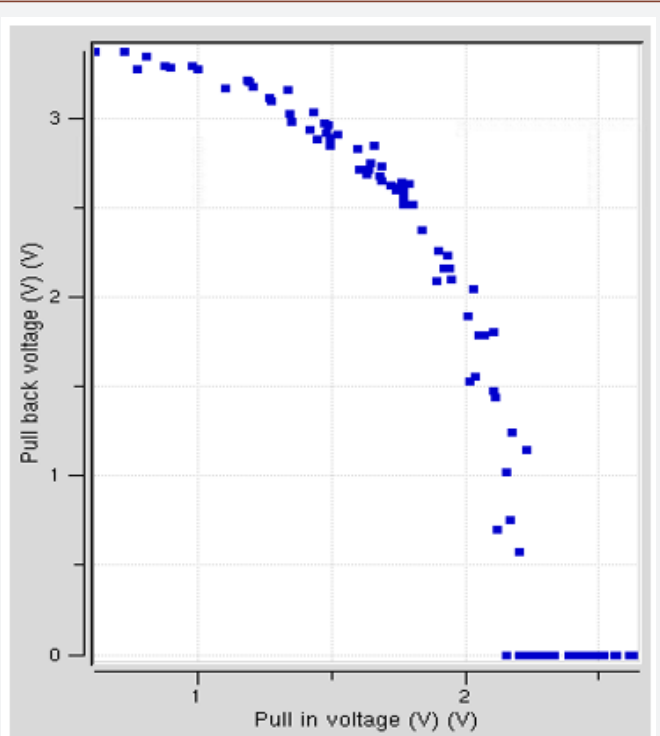

Figure 17: Illustrates pull back voltage vs Pull in voltage for sample 100.
Table 2: Simulation Notes for Carbon Nanotube Relay as 100 Samples.

\begin{tabular}{|c|c|c|}
\hline SI No & Simulation Specifications & Value \\
\hline 1 & Number of samples & 100 \\
\hline 2 & Trench of Electrode material & Gold \\
\hline 3 & Width & $20 \mathrm{~nm}$ \\
\hline 4 & Depth & $100 \mathrm{~nm}$ \\
\hline 5 & Average outer diameter & $4.2 \mathrm{~nm}$ \\
\hline 6 & Standard deviation of other diameter & $1.25 \mathrm{~nm}$ \\
\hline 7 & $\begin{array}{c}\text { Inner diameter to outer diameter } \\
\text { ratio }\end{array}$ & 0.5 \\
\hline 8 & Average length & $100 \mathrm{~nm}$ \\
\hline 9 & Standard deviation of length & $2.25 \mathrm{~nm}$ \\
\hline 10 & Width of contact surface & $2.88 \mathrm{~A}$ \\
\hline 11 & Young's modulus & $1300 \mathrm{Gpa}$ \\
\hline
\end{tabular}

\section{Observations}

- In Figure 10, histogram of outer diameter highest value was $30 @ 3.64444 \mathrm{~nm}$.

- In Figure 11, histogram of inner diameter highest value was $30 @ 1.82222 \mathrm{~nm}$.

- In Figure 12, histogram of length highest value was 39 @ 99.4444nm.

- In Figure 13, pull in voltage vs outer diameter: highest value was 2.64701V @ 6.37558nm and lowest value was 0.608062V@1.72096nm.

- In Figure 14, pull back voltage vs outer diameter: highest value was 3.37725V @ 1.72096nm and lowest value was 0 @ $7.03496 \mathrm{~nm}$.

- In Figure 15, pull in voltage vs length: highest value was 2.64701V @ 97.8694nm and lowest value was 0.608062V @ $101.578 \mathrm{~nm}$.

- In Figure 16, pull back voltage vs length: highest value was 3.38045V@99.6458nm,3.37725V @ 101.578nnm and lowest value was 0V@103.716nm.

- In Figure 17, pull back voltage vs pull in voltage: highest value was 3.37725V @ 0.608062V and lowest value was 0V @ $2.64701 \mathrm{~V}$.

\section{Carbon nanotube relay for 1000 samples}

A simulation for carbon nanotube relay was performed for 1000 samples with electrode material as gold (Figure 18-25) (Table 3).

\section{Observations}

- In Figure 18, histogram of outer diameter highest value was $40 @ 4.55354 \mathrm{~nm}$.

- In Figure 19, histogram of inner diameter highest value was $40 @ 2.27677 \mathrm{~nm}$.

- In Figure 20, histogram of length highest value was 43 @ $100.152 \mathrm{~nm}$.

- In Figure 21, pull in voltage vs outer diameter: highest value was 2.6878V @6.02719nm and lowest value was $0.062553 \mathrm{~V} @ 0.412536 \mathrm{~nm}$. 
- In Figure 22, pull back voltage vs outer diameter: highest value was 3.58182V @ 0.412536nm and lowest value was 0 @ $8.37138 \mathrm{~nm}$.

- In Figure 23, pull in voltage vs length: highest value was 2.6878V@96.5318nm and lowest value was 0.062553V @ $98.3116 \mathrm{~nm}$.

- In Figure 24, pull back voltage vs length: highest value was 3.58182V @ 98.3116nm and lowest value was 0V @ $96.4023 \mathrm{~nm}$.

- In Figure 25, pull back voltage vs pull in voltage: highest value was 3.58182V @0.062553V and lowest value was 0V @ $2.15075 \mathrm{~V}$.

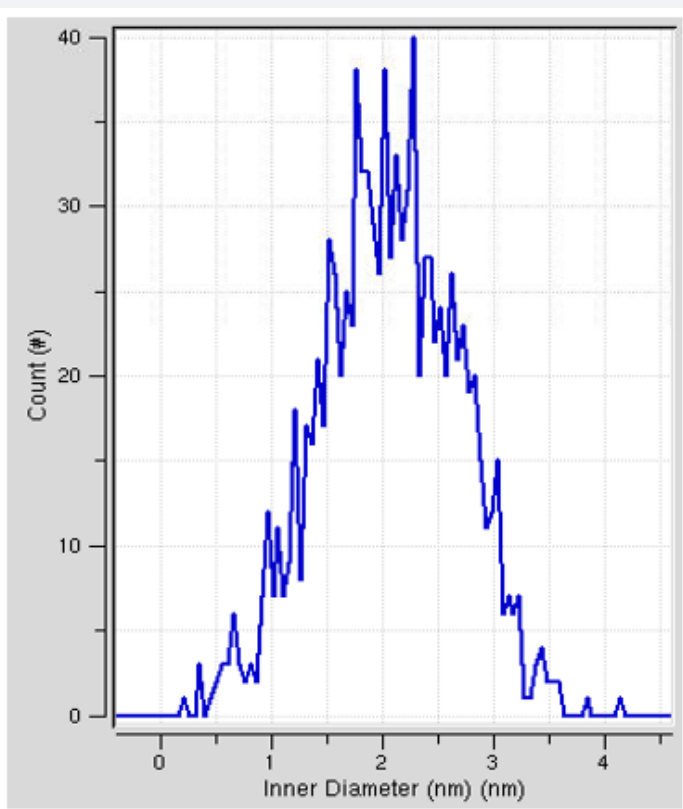

Figure 18: Illustrates Histogram of outer diameters for sample 1000.

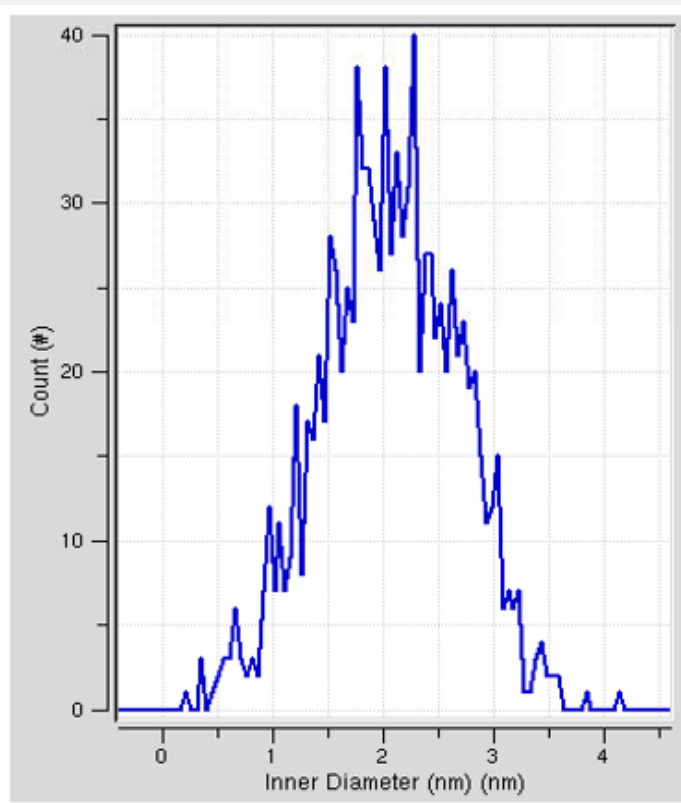

Figure 19: Illustrates Histogram of Inner diameters for sample 1000.

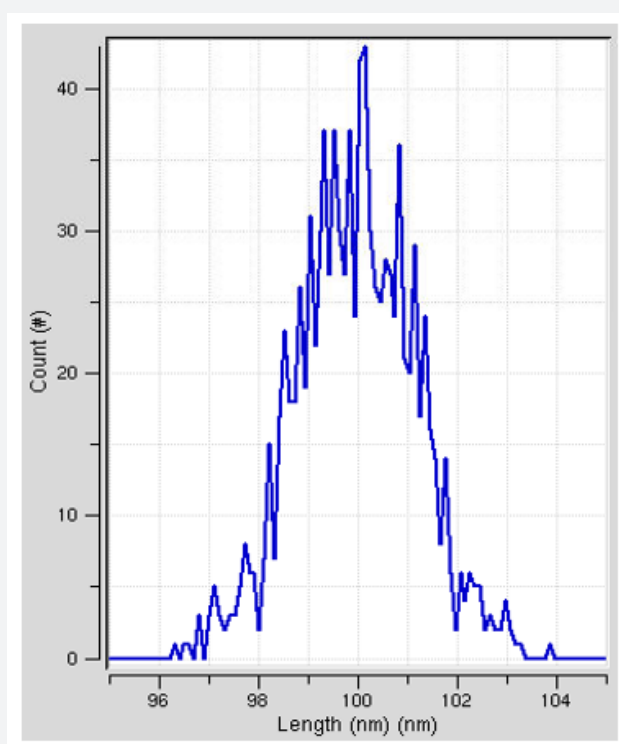

Figure 20: Illustrates Histogram of lengths for sample 1000.

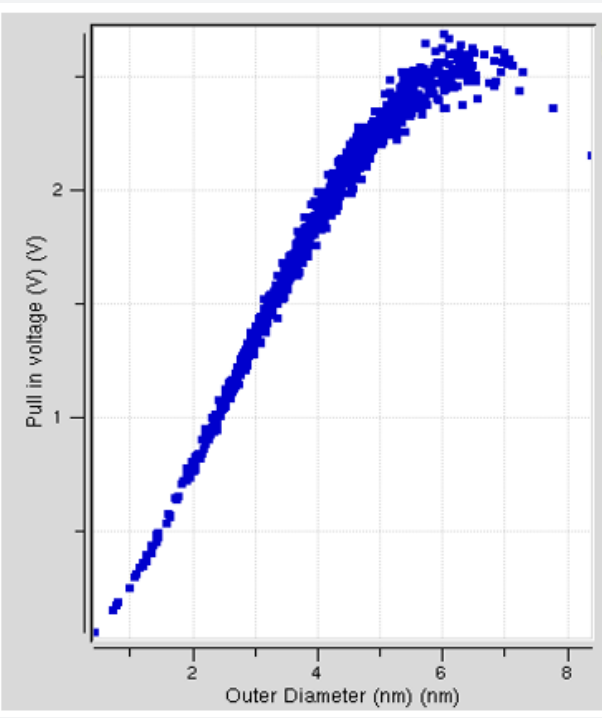

Figure 21: Illustrates pull in voltage vs outer diameter for sample 1000.

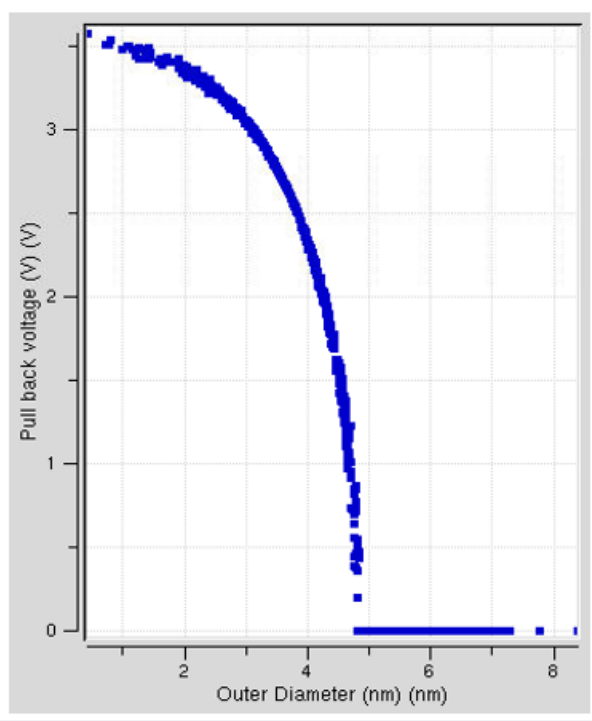

Figure 22: Illustrates pull back voltage vs outer diameter for sample 1000 . 


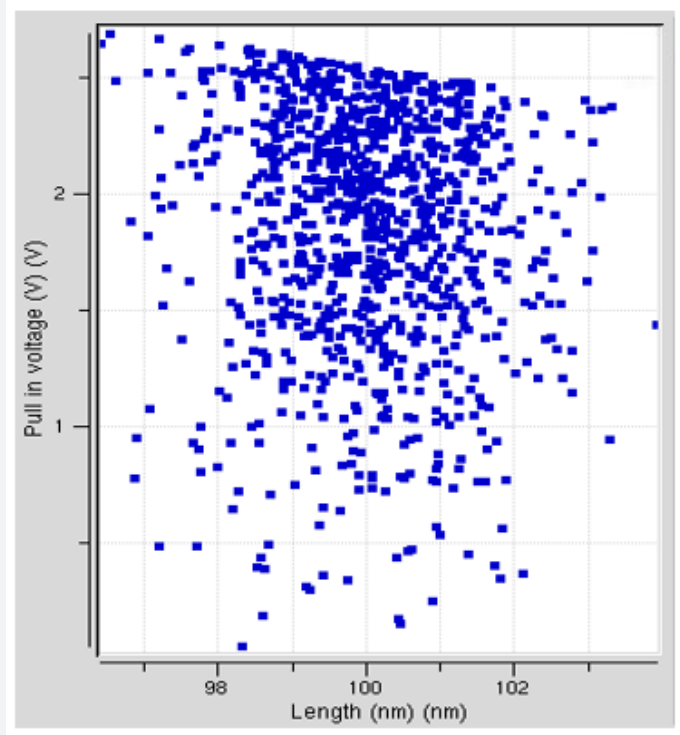

Figure 23: Illustrates Pull back voltage vs length for sample 1000.

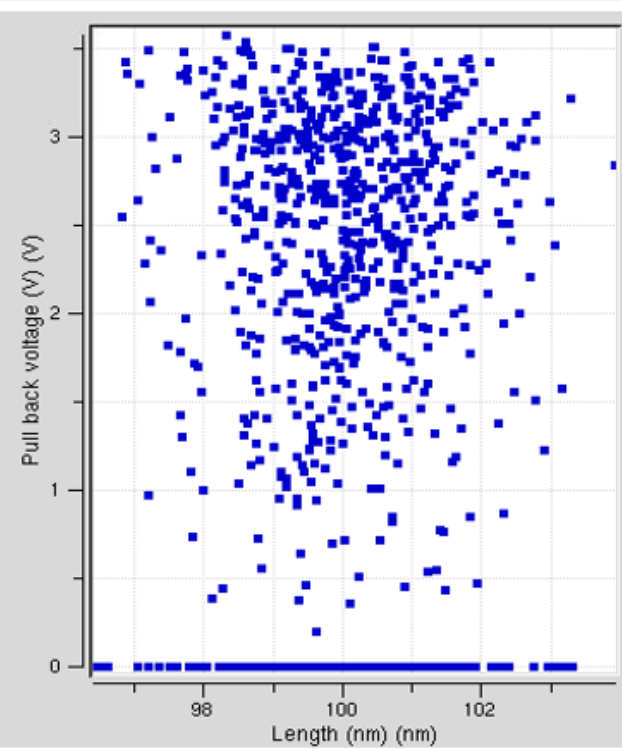

Figure 24: Illustrates Pull back voltage vs length for sample 1000.

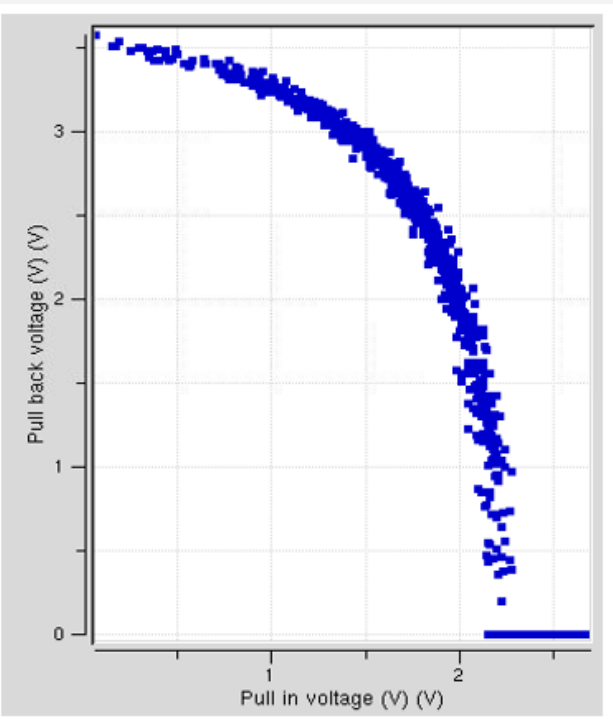

Figure 25: Illustrates pull back voltage vs Pull in voltage for sample 1000 .
Table 3: Simulation Notes for Carbon Nanotube Relay as 10 Samples.

\begin{tabular}{|c|c|c|}
\hline SI No & Simulation Specifications & Value \\
\hline 1 & Number of samples & 1000 \\
\hline 2 & Trench of Electrode material & Gold \\
\hline 3 & Width & $20 \mathrm{~nm}$ \\
\hline 4 & Depth & $100 \mathrm{~nm}$ \\
\hline 5 & Average outer diameter & $4.2 \mathrm{~nm}$ \\
\hline 6 & Standard deviation of other diameter & $1.25 \mathrm{~nm}$ \\
\hline 7 & Inner diameter to outer diameter ratio & 0.5 \\
\hline 8 & Average length & $100 \mathrm{~nm}$ \\
\hline 9 & Standard deviation of length & $2.25 \mathrm{~nm}$ \\
\hline 10 & Width of contact surface & $2.88 \mathrm{~A}$ \\
\hline 11 & Young's modulus & $1300 \mathrm{Gpa}$ \\
\hline
\end{tabular}

\section{Carbon nanotube relay for 10000 samples}

A simulation for carbon nanotube relay was performed for 10000 samples with electrode material as gold (Figure 26-33) (Table 4).

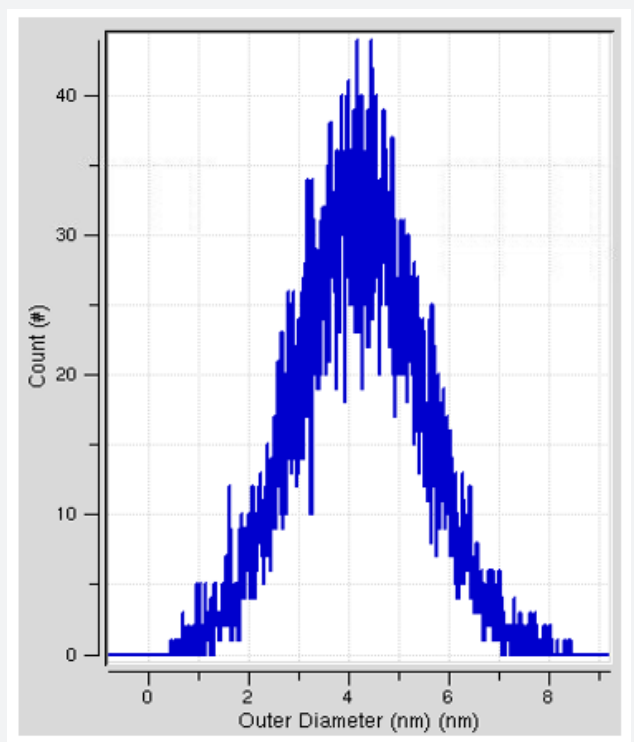

Figure 26: Illustrates Histogram of outer diameters for sample 10000 .

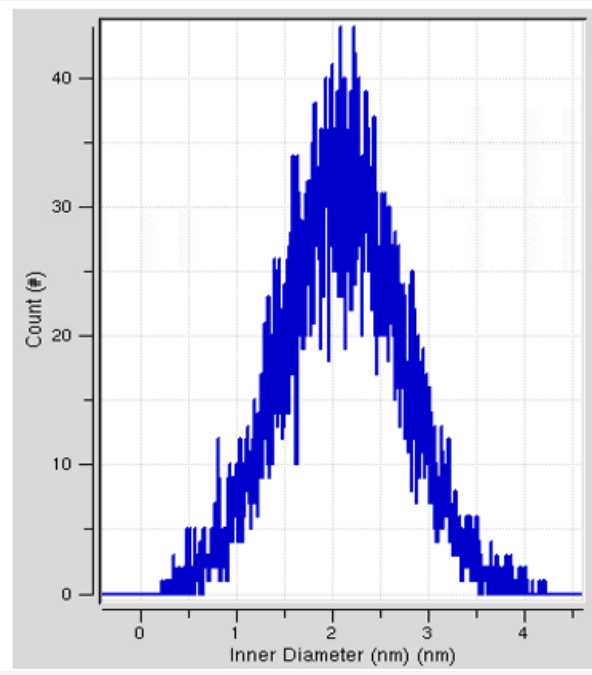

Figure 27: Illustrates Histogram of Inner diameters for sample 10000. 


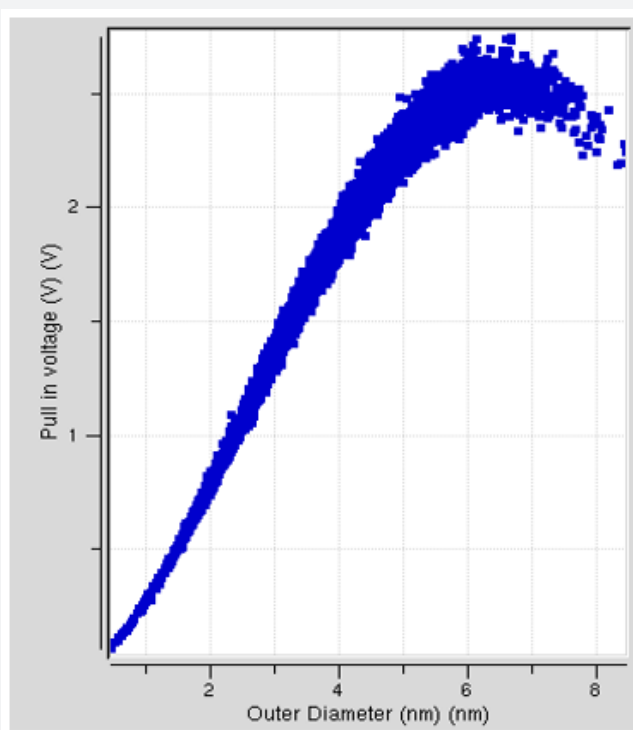

Figure 28: Illustrates Histogram of lengths for sample 10000.

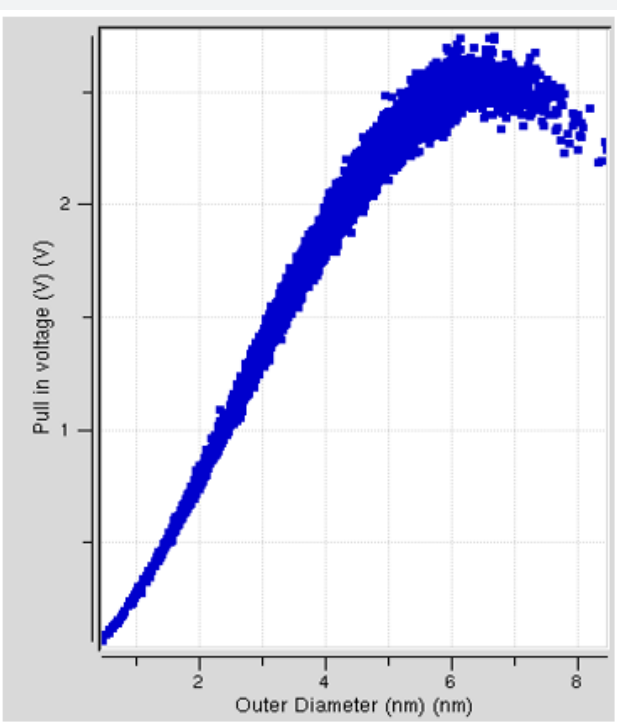

Figure 29: Illustrates pull in voltage vs outer diameter for sample 10000.

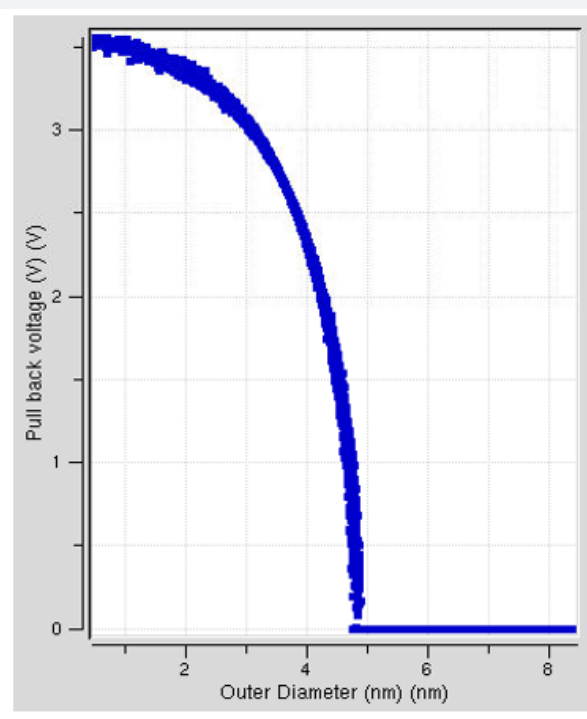

Figure 30: Illustrates pull back voltage vs outer diameter for sample 10000 .

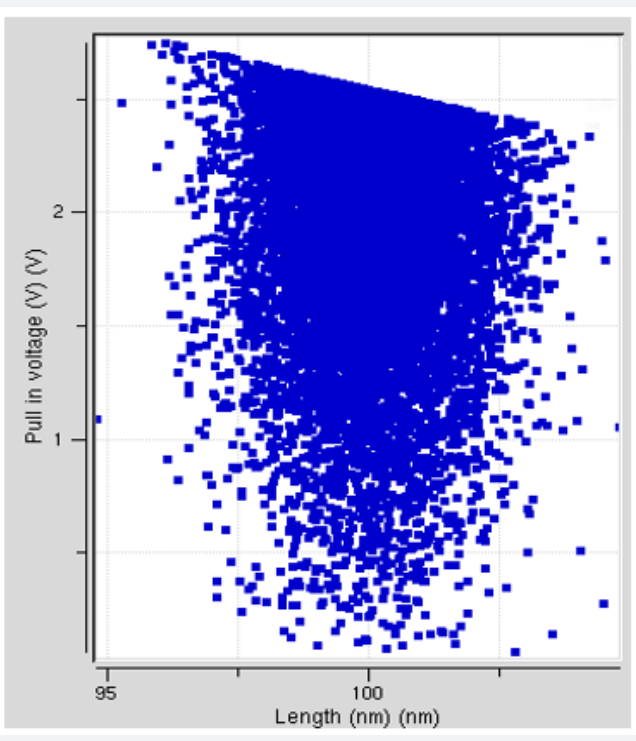

Figure 31: Illustrates Pull in voltage vs length for sample 10000.

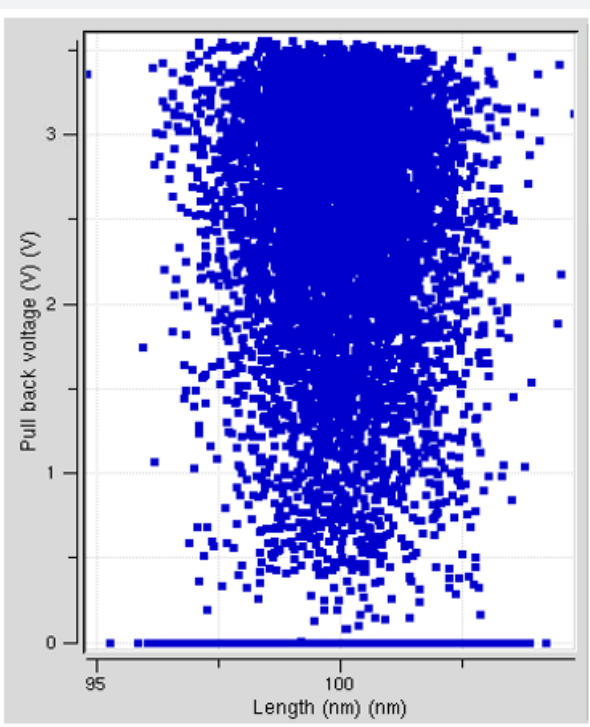

Figure 32: Illustrates Pull back voltage vs length for sample 10000.

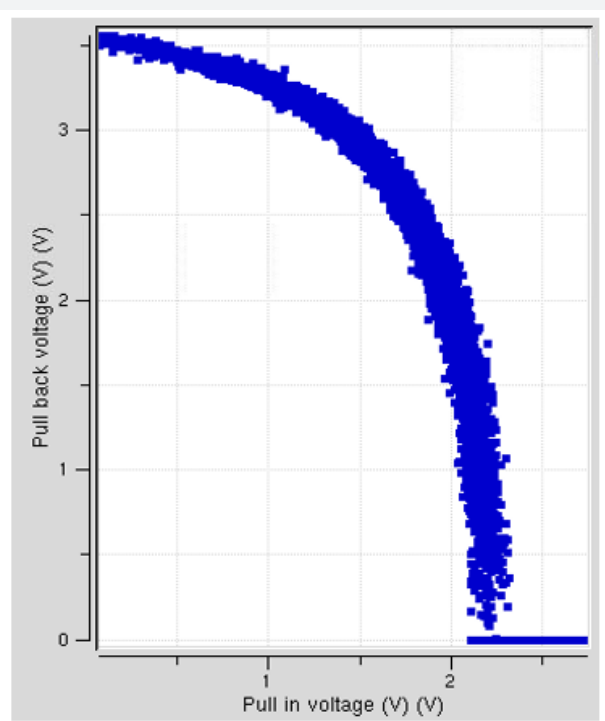

Figure 33: Illustrates pull back voltage vs Pull in voltage for sample 10000 . 
Table 4: Simulation Notes for Carbon Nanotube Relay as 10000 Samples.

\begin{tabular}{|c|c|c|}
\hline SI No & Simulation Specifications & Value \\
\hline 1 & Number of samples & 10000 \\
\hline 2 & Trench of Electrode material & Gold \\
\hline 3 & Width & $20 \mathrm{~nm}$ \\
\hline 4 & Depth & $100 \mathrm{~nm}$ \\
\hline 5 & Average outer diameter & $4.2 \mathrm{~nm}$ \\
\hline 6 & Standard deviation of other diameter & $1.25 \mathrm{~nm}$ \\
\hline 7 & $\begin{array}{c}\text { Inner diameter to outer diameter } \\
\text { ratio }\end{array}$ & 0.5 \\
\hline 8 & Average length & $100 \mathrm{~nm}$ \\
\hline 9 & Standard deviation of length & $2.25 \mathrm{~nm}$ \\
\hline 10 & Width of contact surface & $2.88 \mathrm{~A}$ \\
\hline 11 & Young's modulus & $1300 \mathrm{Gpa}$ \\
\hline
\end{tabular}

\section{Observations}

- In Figure 26, histogram of outer diameter highest value was $44 @ 4.18498 \mathrm{~nm}$ and $44 @ 4.44525 \mathrm{~nm}$.

- In Figure 27, histogram of inner diameter highest value was $44 @ 2.09249 n m$ and $44 @ 2.22262 n m$.

- In Figure 28, histogram of length highest value was 46 @ $100.215 \mathrm{~nm}$.

- In Figure 29, pull in voltage vs outer diameter: highest value was 2.75027V @6.67245nm.

- In Figure 30, pull back voltage vs outer diameter: highest value was 3.55944V@0.51333nm and lowest value was 0.0801063V@4.82676nm.

- In Figure 31, pull in voltage vs length: highest value was 2.75027V@96.1257nm and lowest value was 0.0675541V @ $102.794 \mathrm{~nm}$.

- In Figure 32, pull back voltage vs length: highest value was 3.55944V@99.0319nm and lowest value was 0V @ 95.282nm.

- In Figure 33, pull back voltage vs pull in voltage: highest value was 3.55944V@0.0898375V and lowest value was $0.0801063 \mathrm{~V} @ 2.21085 \mathrm{~V}$.

\section{Results}

What is claimed in this research article are
1. Carbon nanotube Relay characteristics of histogram of outer diameters, histogram of inner diameters, histogram of lengths, pull in voltage vs outer diameter, pull back voltage vs outer diameter, pull in voltage vs length, pull back voltage vs length, pullback voltage vs pull in voltage with 10, 100, 1000 and 10000 samples have been performed.

2. Highest peak values and lowest values for the samples are noted.

\section{Conclusion}

Carbon Nanotube has only few nanometers in diameter and more than millimeters in length that gives remarkable properties in nanoscale relay compared to traditional materials. Not to mention its tensile strength is greater than steel, conductivity is greater than copper, thermal dissipation is greater than diamonds and it is resistance to corrosion.

\section{Discussion}

In this research article all the values are taken as default values which are documented in Tables. Results, lengths, graph, voltages etc., vary for the change in the values. Author also want to take note: whenever samples are increasing outer diameter, inner diameter, length of samples, pull in voltage versus length of sample, pull back voltage versus length of sample, pull in voltage versus pull back voltage are changing significantly. For instance, in Fig 31, Pull in voltage versus length shows lot of values for 10000 samples which makes an ideal for a carbon nanotube relay.

\section{Acknowledgment}

Author would like to thank Prof. Navarun Gupta, Prof. Hassan Bajwa, Prof. Linfeng Zhang and Prof. Hmurcik for their academic support. Author also thanks anonymous reviewers for their comments.

\section{Conflicts of Interest}

There are no conflict of interest as per Author's point of view.

\section{References}

1. Donatello A, Adrian IM (2010) Nano-Electro-Mechanical Switches Based on Carbon Nanotubes Arrays.

2. Kaul A, Epp L, Wong E (2008) Carbon nanotube mechanical relays for electronics.

3. Sansiri Tanachutiwat, Wei wang (2015) Carbon Nanotube Relay. 